\title{
Reflexões sobre a hiperspecialização científica e suas consequências para a geografia
}

\author{
Reflections on scientific hyperspecialization and its consequences for geography
}

Francisco de Assis Gonçalves Junior*

Thamires Cristine Corrêa**

\section{Resumo:}

Este artigo visa discutir o contexto histórico e filosófico responsável pela origem do conceito que Edgar Morin define em sua obra $A$ cabeça bem-feita: repensar a reforma, reformar o pensamento como, a "hiperspecialização" da análise científica, ou em outras palavras, a especialização que se fecha em si mesma, que fragmenta a realidade e que impede o pesquisador de conceber o global. Considerou-se como premissa que a origem desta segregaçâo analítica advém das formas de pensamento oriundas da supervalorização da razão humana. Para análise desta conjectura foram considerados dois pensadores: René Descartes e Isaac Newton. Apresentaremos também algumas reflexôes sobre a problemática da hiperespecialização científica na análise geográfica, principalmente no que tange a hiperespecialização organizada em torno da matemática/geometria, uma vez que a Geografia, devido a seu objeto de estudo (relaçáo homem-sociedade/natureza), possui sua construção epistemológica pautada em questionamentos complexos e até mesmo subjetivos, ou seja, situaçôes que demandam formas de análise multidimensionais, e que portanto, não apresentam coesão quando demasiadamente fragmentadas. Neste bojo, considera-se que a atuação de profissionais hiperespecializados (tanto licenciados como bacharéis) tem diluído a unidade da Geografia enquanto ciência voltada a uma compreensão ampla da realidade social.

\begin{abstract}
:
This article aims at debating the historical and philosophical context accountable for the origin of the concept that Edgar Morin defined in his writing The well-made head: rethinking reform, reforming thinking as the "hyperspecialization" of scientific analysis, or, in other words, the specialization that closes in on itself, that fragments reality and that prevents the researcher from conceiving the global. It was considered as a premise that the origin of the analytic segregation comes from the forms of thought originated from the overvaluation of human reason. For the analysis of such conjecture two thinkers were considered: René Descartes and Isaac Newton. We will also present some reflections on the problem of scientific hyperspecialization in the geographic analysis, especially regarding the organized hyperspecialization in mathematics/geometry, since Geography, (relation man-society / nature), has its epistemological construction based on complex and even subjective questioning, i.e., situations that require multidimensional forms of analysis, and which therefore do not present cohesion when they are too fragmented. In this context, I consider that the performance of hyper-specialized professionals (both graduates and bachelors) has diluted the unit of Geography as a science geared to a broad understanding of social reality.
\end{abstract}

*Docente do Departamento de Geografia - UFMT Universidade Federal de Mato Grosso Cuiabá/MT

**Mestranda no Programa de Pós-Graduação em Geografia - UFMT Universidade Federal de Mato Grosso Cuiabá/MT

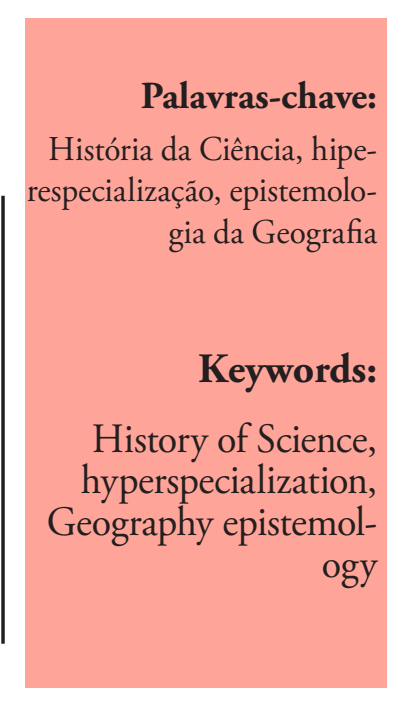




\section{INTRODUÇÁO}

A obra, A cabeça bem-feita: repensar a reforma, reformar o pensamento, de Edgar Morin, publicada originalmente em 1999, busca apresentar uma reflexão sobre a necessidade de superação do paradigma moderno de ciência, entendida como aquela que em sua análise acaba por parcelar a realidade, mesmo quando as problemáticas demandam perspectivas multidimensionais, ou seja, demandam respostas mais globais (no sentido do entendimento de todos os processos), portanto mais complexas.

Este parcelamento da realidade promovido pela ciência moderna acabou conduzindo também a compartimentação das disciplinas escolares (em todos os níveis de ensino) e que por sua vez acabaram enraizando culturalmente a noção de que ciências exatas, humanas, biológicas e artes, não apresentam uma correlação usual, pois não possuem objetos comuns de análise. Dessa forma, o parcelamento da realidade não conduz apenas a especialização e compartimentação do saber, mas também a sua segregação em relação a outras formas de compreensão da realidade, fato que causa, como destacado por Morin (2014, p.15) "ignorância e cegueira".

Sobre esta forma de compreensão da realidade Morin (2014) ainda destaca:

\begin{abstract}
Efetivamente, a inteligência que só sabe separar, fragmenta o complexo do mundo em pedaços separados, fraciona os problemas, unidimensionaliza o multidimensional. Atrofia as possibilidades de compreensão e de reflexão, eliminando assim as oportunidades de julgamento corretivo ou de uma visão a longo prazo. Sua insuficiência para tratar nossos problemas mais graves constitui um dos mais graves problemas que enfrentamos (MORIN, 2014, p.14).
\end{abstract}

A partir destas colocaçóes Morin vai estabelecer um longo diálogo combativo à ciência hiperespecializada, propondo nesse processo a necessidade de apropriaçáo de um novo paradigma, uma nova forma de se pensar, pautado na globalidade e na complexidade das problemáticas contemporâneas.

Morin (2014, p.13) em seu discurso define a hiperespecialização como a "especialização que se fecha em si mesma sem permitir sua integração em uma problemática global ou em uma concepção de conjunto do objeto que ela considera apenas um aspecto" ${ }^{1}$, em outras palavras a hiperespecializaçáo é a especialização que impede a apreensão do global, pois fragmenta a realidade diluindo sua essência.

Com base nessa delimitação conceitual buscou-

1 Página 13, nota de rodapé da obra. -se apresentar em primeiro momento, uma reflexão sobre a origem histórica e filosófica da hiperspecialização trabalhada por Morin, principalmente no que se refere a hiperespecializaçáo advinda da matemática, tendo como ênfase o Renascimento e o nascimento da Ciência Moderna. Em seguida buscamos apresentar uma análise crítica da influência da hiperspecialização científica (especialmente a derivada da matemática) na Geografia, tanto em seu viés combativo, realizado através da proposição de análises integradas interdisciplinares construídas a partir de um objetivo comum, como em seu viés apropriativo verificado através de uma crescente hiperespecialização metodológica interna. Neste bojo também foram estabelecidas reflexóes sobre as consequências da hiperspecialização científica para o ensino da Geografia no Brasil, tanto no Ensino Básico como no Ensino Superior.

As reflexôes apresentadas pelos autores neste artigo se assentaram sobre um inquietamento epistemológico emergido de suas próprias vivências formativas e de exercício profissional. Portanto não foram definidas metodologias rígidas de pesquisa, não em termos cartesianos (o que inclusive seria contraditório frente a reflexão abordada), o que buscamos foi, através de uma profunda análise bibliográfica, contextualizar e assim compreender a origem de algumas de nossas inquietaçôes atuais.

\section{A CIÊNCIA RACIONAL}

Consideramos que o modelo de racionalidade que preside a Ciência Moderna, e que adentra a atualidade com pouquíssimas modificaçóes, teve sua origem na Revolução Científica iniciada no século XVI, momento em que a racionalidade tornou-se o principal paradigma científico na interpretação dos fenômenos do mundo, instituindo em termos metodológicos um modelo global de análise, pautado no domínio das ciências naturais. Sua consolidação enquanto modelo global delimitaria também sua ascensão enquanto modelo totalitário de ciência, que, segundo Santos (2008):

[...] nega o caráter racional a todas as formas de conhecimento
que se náo pautarem pelos princípios epistemológicos e pelas
suas regras metodológicas. É esta a sua característica fundamen-
tal e a que melhor simboliza a ruptura do novo paradigma cien-
tífico com os que o precedem (SANTOS, 2008, p. 21).

As regras deste modelo seriam balizadas pela razão matemática, seu principal instrumento lógico, responsável tanto pela composição das ideias como pela 
análise experimental dos fenômenos naturais observados, sendo a única capaz de delimitar leis universais.

No entanto este constructo epistemológico pautado na centralidade matemática causaria, segundo Santos (2008), duas consequências para a ciência de forma geral:

Em primeiro lugar, conhecer significa quantificar. O rigor científico afere-se pelo rigor das mediçôes. As qualidades intrínsecas do objecto são, por assim dizem, desqualificadas e em seu lugar passam a imperar quantidades em que eventualmente se podem traduzir. O que não é quantificável é cientificamente irrelevante. Em segundo lugar, o método científico assenta na reduçáo da complexidade (SANTOS, 2008, p.28).

Neste bojo, Descartes talvez tenha sido o maior expoente, pois seu método adentraria os altos escalóes científicos da modernidade, delimitando até mesmo em nível de senso comum, o significado do termo ciência. Torna-se importante destacar que a amplitude do método cartesiano culminou inclusive em sua aplicação as ciências humanas e sociais, como é o caso, por exemplo, dos cálculos estatísticos em busca de padróes populacionais, de migração, etc.

Descarte definiu que o método científico deveria priorizar a divisão e classificação dos elementos que compóem os fenômenos naturais para assim determinar em uma nova etapa as relaçóes sistemáticas estabelecidas entre aquilo que fora separado, para finalmente proceder a recomposição do fenômeno, "começando pelos objetos mais simples e mais fáceis de conhecer, para subir aos poucos, como por degraus, até o conhecimento dos mais compostos (DESCARTES, 2011, p.55). A partir de suas colocaçóes abrem-se as portas para as especializaçóes e hiperespecializaçóes.

Estes, que constituem o segundo e o terceiro princípios presentes no Discurso sobre o Método de Descartes, delineiam respectivamente na ciência moderna a separação e a redução da realidade.

Sobre este aspecto, Morin (2014) aponta que:

O princípio da redução comporta duas ramificaçôes. A primeira é a da reduçáo do conhecimento do todo ao conhecimento adicional de seus elementos. [...] A segunda ramificação do princípio de redução tende a limitar o conhecimento ao que é mensurável, quantificável, formulável, com ajuda de quantidades mensuráveis. Desde então, a redução ao quantificável condena todo conceito que nâo seja traduzido por uma medida. Ora, nem o ser, nem a existência, nem o sujeito podem ser expressos matematicamente ou por meio de fórmulas (MORIN, 2014, p.88).
Dessa forma percebemos que a Ciência Moderna em seu modelo totalitário acabava por "retirar" o homem do mundo.

A interpretaçáo do cogito ergo sum cartesiano modificaria definitivamente a relação entre o homem e natureza. O homem, único ser da criação dotado de razão passaria a ver a natureza como algo a ser "dominado", em outras palavras, a natureza por si só em seu devir natural "irracional” seria inferior ao homem.

Santos (2008) destaca que a natureza nesta perspectiva:

[...] é tấo-só extensão e movimento; é passiva, eterna e reversível, mecanismo cujos elementos se podem desmontar e depois relacionar sob a forma de leis; não tem qualquer outra qualidade ou dignidade que nos impeça de desvendar os seus mistérios, desvendamento que é activo, já que visa conhecer a natureza para a dominar e controlar. Como diz Bacon, a ciência fará da pessoa humana "o senhor possuidor da natureza" (SANTOS, 2008, p.25).

A ideia de que as criaturas inferiores (tanto fauna como flora) teriam sido criadas para o usufruto do homem perdurou ao longo dos séculos.

No século XVIII, insistia-se amplamente em que a domesticaçáo era benéfica para os animais [...]. Vacas e ovelhas passavam melhor sob os cuidados do homem que deixadas à mercê de predadores ferozes. Abatê-las par alimento podia parecer cruel, dizia Thomas Robinson em 1709, mas, "quando se examina o assunto mais de perto", isso se mostrava "uma gentileza em vez de crueldade"; o seu fim era rápido e se lhes poupava os sofrimentos da idade. Náo havia injustiça quanto a matar o gado para fornecer alimento para "um animal mais nobre", pensava o arcebispo King; foi apenas por essa razão que as bestas foram criadas antes de nós (THOMAS, 1988, p.25).

Torna-se importante destacar que este domínio também justificou as expansões imperialistas ocorridas entre os séculos XVI e XIX, sobre as "raças inferiores" da África e da Índia, por exemplo, no entanto, este seria assunto para um novo artigo ${ }^{2}$.

Dessa forma, ao analisarmos a conjectura científica atual, podemos afirmar que pouco mudou, pois a ciência dominante (em número de institutos de pesquisa, pesquisadores e linhas de financiamento) deriva

2 Sobre o assunto: GEBARA, A. L. A. A África no discurso de Richard Francis Burton: uma analise da construçáo de suas representaçôes. São Paulo: Tese (Doutorado em História). Faculdade de Filosofia, Letras e Ciências Humanas, Universidade de São Paulo - USP, 2007. 
prioritariamente do método preconizado por Descartes em 1637, claramente organizada em dois eixos de desenvolvimento: o primeiro, ético, vinculado ao domínio da natureza para usufruto do homem, portanto de caráter utilitarista, e o segundo, metodológico, vinculado a divisão e sistematização matemática da natureza.

\section{O ESPAÇO ABSOLUTO NEWTONIANO}

Em 1687 Isaac Newton publicava sua magnum opus, o Philosophiae Naturalis Principia Mathematica, na qual apresentava em detalhes as regras de funcionamento do mundo-máquina, tendo como parâmetro inquestionável para isso a formulação e utilização de leis universais (matemáticas) muitas das quais descobertas por ele ao longo de seus anos de estudo em Cambridge.

Dessa obra, enfatizaremos apenas a construção do conceito de espaço absoluto, por entender que é justamente ele quem reforça a noção de espaço geométrico trabalhado pela Geografia dos séculos XVII e XVIII em grande parte do ocidente (exclui-se a Alemanha pré-Bismarck). Dessa forma buscamos demonstrar que a noção de espaço newtoniana, ainda atual em grandes centros de formação de profissionais, acabara conduzindo a Geografia a uma leitura pouco crítica da realidade social ou até mesmo da realidade ambiental, associando a Geografia a um cabedal de técnicas voltadas aos mapeamentos de precisão.

Em sua formação Newton analisou os escritos de Henry More sobre o conceito de espaço. More entendia que a extensão seria um elemento divino, resultado da união entre o espaço, configurado como pura extensão imaterial, preexistente a matéria, e o "espírito da natureza", entendido por More como o poder de Deus sobre a matéria.

More dessa forma desarticula a existência do espaço da existência da matéria, no entanto é sobre este espaço que ocorreria a potencialidade da matéria através das leis universais. "Esse espaço tem sua existência garantida, não pela presença de matéria, mas pela manifestação da ação divina (espírito da natureza)" (LOURES, 2010, p.18).

O espaço "divinizado" de More seria pré-existente e independente da matéria e sobre ele atuariam as leis universais que foram criadas por
Deus, ou em outras palavras, "o espaço seria a "morada” do espírito da natureza” (LOURES, 2010, p.18).

Newton apesar de ser avesso a qualquer tipo de misticismo no entendimento da natureza não considerava as colocaçóes de More sobre o espaço como místicas, já que elas poderiam ser balizadas pela matemática (principalmente pela geometria). Nesse sentido, o conceito de espaço como algo absoluto (como definiria Newton), serviria como ferramenta conceitual para elaboraçáo de suas teorias científicas.

Neste bojo, torna-se importante destacar que Newton fora criado no seio de uma família protestante e ao seu modo nunca deixou de ser temente a Deus.

Grosso modo, o protestantismo do século XVIII vinculava-se muito mais com a busca pela compreensão da obra divina em si (causa eficiente), do que pela compreensão dos verdadeiros desígnios divinos (causa primária) no processo de formação do universo e da matéria, o que por sua vez acabaria reforçando o uso da razáo pelos cientistas alinhados a ética protestante (homem como único ser da criação dotado de razão).

Em síntese, o espaço absoluto seria divino e imutável, sobre ele atuariam as leis universais regidas pelo "espírito da natureza" e que poderiam ser compreendidas pela matemática, leis estas que modificariam a matéria e que por sua vez poderiam ser analisadas através de experimentos controlados.

O espaço absoluto de Newton, considerado como uma entidade imutável atuaria como um "pano de fundo fixo" para o movimento dos corpos celestes, este movimento absoluto seria o movimento verdadeiro, (a Terra estaria em movimento relativo em relação a outro referencial de observação, como a Lua, por exemplo, no entanto estaria em movimento absoluto em relaçáo ao espaço absoluto). O movimento absoluto se dá em relação ao espaço absoluto, definindo o lugar absoluto das coisas. Como exemplo podemos citar que a Terra em seu plano de translação ao redor do Sol, teria seu lugar no espaço absoluto em determinado momento. Justamente a característica transitória do lugar absoluto em relação ao momento, ou seja, a mudança constante de lugar que caracteriza a translação da Terra ao redor do Sol, definiria por sua vez algumas das leis universais que regem o "sistema mundo", fato que permitiria a análise das cau- 
sas e efeitos derivados desse movimento nos elementos da natureza (matéria), portanto não é o espaço absoluto quem determina as transformaçóes da matéria (pois este atua apenas como receptáculo) e sim as leis universais que atuam neste espaço.

As descobertas revolucionárias de Newton causaram um imenso fervor entre os cientistas naturais da época, tornando-o um dos mais importantes nomes do século XVIII.

Torna-se importante destacar também o papel da obra Geografia Geral de 1650 (não acabada) do alemáo Bernhadus Varenius (1621/1622-1650) na concepçáo das teorias de Newton.

Varenius foi sem dúvida o primeiro autor da Geografia a absorver no âmbito teórico-metodológico as inovaçóes da ciência moderna, fato associado ao período em que viveu, como destaca Bauab (2011).

O cenário histórico existente à época de Varenius teve por característica [...], a eclosão de uma série de eventos que podem ser considerados extremamente importantes para a irrupçáo da modernidade: a eclosão da Reforma Protestante e a cisão inédita inserida por ela na Cristandade; o surgimento e a consolidação dos Estados Nacionais; a gênese da Ciência Moderna com a contribuição de autores de autores como Johannes Kepler e Galileu Galilei; a aproximação da filosofia com as problemáticas ensejadas pela ciência nascente através das obras de F. Bacon e Descartes; o mercantilismo estimulado, em parte, pelas conquistas ultramar dos chamados Descobrimentos Marítimos (BAUAB 2011, p. 195).

Em sua obra Varenius dividia a Geografia em duas partes, a Geografia Geral que considerava a Terra enquanto conjunto e buscava compreender suas propriedades, no entanto sem se ater as particularidades das regióes, e a Geografia Especial que buscava compreender justamente a constituição das regiôes, sendo estas subdivididas entre estudos corográficos e estudos topográficos (Bauab, 2011).

Newton mesmo se deparando com vários elementos da física cartesiana, superada por ele, organizou duas ediçóes da Geografia Geral de Varenius, uma em 1672 e outra em 1681. No entanto, em ambas as ediçóes foram acrescentadas questóes de debate envolvendo o cartesianismo presente na obra e os conteúdos advindos das descobertas de Newton, como destaca Bauab (2011).

[...] podemos ressaltar amparados em Warntz (1989), que Newton e os newtonianos trataram, desde a edição de 1672 , de, sem macular esquemas e conteúdos eminentemente cartesianos, acrescentar idéias vinculadas às descobertas físicas que realizavam. Warntz (1989) ressalta que os esquemas e tabelas acrescentados por Newton, desde a edição de 1672, incluem aspectos referentes a matemática pura (Geometria aplicada à Geografia) e à matemática mista, abrangendo estudos de temas como refração da luz, altitudes, tempo, navegaçáo, cartografia, projeçôes, entre outros (BAUAB, 2011, p. 216).

Dessa forma torna-se claro o profundo interesse de Newton pela obra de Varenius, assim como sua tentativa de proporcionar um fecundo debate através de novas proposiçóes, principalmente no que se refere ao conteúdo da Geografia Geral referente a Matemática Mista, entendida por Varenius como a matemática que "explicaria as propriedades da Terra e de suas partes relativas à quantidade, isto é, figura, situação, dimensóes, movimentos, fenômenos celestes e outras propriedades similares" (BAUAB, 2011, p. 214). O interesse de Newton também se dá pelo fato da obra de Varenius apresentar uma Geografia de caráter utilitarista, elaborada frente a crescente demanda por exatidáo dos pontos do globo.

Neste bojo, o conceito de espaço absoluto de Newton, adaptado em nível de análise escalar para os elementos terrestres, tornar-se-ia fundamental para as pretensóes utilitaristas de uma Geografia que buscava a exatidão.

As representaçóes da Terra e seus elementos através da criação de cartas topográficas descreviam um espaço que não apresentava relação direta com a matéria presente neste espaço, ter-se ia, portanto, um espaço isotrópico, considerado apenas como receptáculo da matéria existente na Terra.

$\mathrm{Na}$ verdade, Newton, no que se refere a localização precisa dos elementos, utiliza como base a noção geométrica de Descartes, em que todos os elementos do mundo circundante teriam uma extensão (altura, comprimento e largura). A res extensa de Descartes poderia ser definida matematicamente aferindo a forma identificada uma localização precisa, o espaço nesse caso seria apenas um dado universal da existência, ou como em More, uma extensão imaterial.

Sob este contexto, a noção de espaço absoluto de Newton permitiu conceitualmente que a Geografia se debruçasse ainda mais sobre o método euclidiano/ cartesiano, no que se refere aos aspectos métricos do espaço, fato que nos permite afirmar que a Geografia desse período, em grande parte do ocidente, não tratava do espaço geográfico como entendemos hoje e sim do espaço cartográfico e topográfico de cunho geométrico, voltado apenas a descrição dos elementos em relação a sua localização, a leitura relacional dos objetos estaria em um segundo plano. 
Sobre isso Fonseca e Oliva (2001) destacam que:

Em termos de cartografia, considerada a ideia de espaço absoluto, ela pode ir pouco além de uma representaçáo descritiva do espaço geográfico, atuando com o mais absoluto rigor com as métricas euclidianas. Disso resulta uma Cartografia de localização rigorosa dos objetos geográficos que, quando correlaciona objetos, o faz nos limites da distância euclidiana. Por isso, essa cartografia é forte no registro e na descrição rigorosa das distâncias euclidianas (FONSECA \& OLIVA, 2001, p.74).

A Geografia via espaço absoluto apresentava, portanto, um forte laço utilitarista com a Geografia entendida enquanto Matemática Mista, como afirmava Varenius em sua Geografia Geral, principalmente no que se refere a localizaçáo precisa dos elementos, como destaca Bauab (2005):

\begin{abstract}
A geografia na ótica do autor, seria um ramo da matemática mista, ordenando na superfície geral, toda do planeta - dai o título de Geografia Geral - seus elementos constituintes. Daí a classificação precisa do que seria um monte, uma jazida, uma laguna, um lago, um pântano, ventos, rios, montanhas... Estaria, segundo o próprio Varenius, a matemática colocada enquanto a priori básico de todas as ciências, do entendimento dos fenômenos, ordenando-os, no caso da Geografia, espacialmente, isto em termos de uma localização precisa, inconteste (BAUAB, 2005, p.302-303).
\end{abstract}

Assim, esta Geografia dos séculos XVIII e XIX, de cunho cartográfico, portanto técnico e utilitarista, não visava estabelecer um constructo epistemológico voltado a emancipação da Geografia enquanto ciência, pois estava condicionada exclusivamente as necessidades de informaçáo e de dados, dividindo a realidade em parcelas localizáveis sem necessariamente estabelecer relaçóes, a Geografia não era entendida de outra forma, fato que não nos permite julgar o entendimento concebido por Varenius como certo ou errado.

No entanto, a questấo que nos surge é que o mapa, entendido atualmente pelos geógrafos como uma ferramenta para análise do espaço geográfico, continua em alguns casos sendo confundido com o próprio objeto de estudo da Geografia, ou seja, se estrutura sobre a mesma base advinda de Descartes/Varenius/Newton. Esta compreensão errônea se enraizou devido ao prestígio alcançado por estes cientistas, que por sua vez acabaram definindo de forma totalitária o modelo de ciência a ser seguido. Nesse processo os primeiros geógrafos (anteriores a constituição da Geografia como ciência) acreditavam que a Geografia ao seguir os parâmetros ditados pela Ciência Moderna estaria garantindo tanto sua legitimidade enquanto área do conhecimento como seu lugar de apoio entre as ciências naturais.

$\mathrm{Na}$ verdade este nem deveria ser um problema a ser discutido, uma vez que a Geografia em sua própria consolidação como ciência no século XIX (que supera seu status de ciência de apoio), assim como em sua própria evoluçáo epistemológica, se assentou sobre outro conceito de espaço, alterando o foco do espaço absoluto para o espaço relacional, ou geográfico. No entanto, o conceito de espaço absoluto continua sendo utilizado por diversos grupos de pesquisa em Geografia, não só no Brasil.

\section{A CRISE DA CIÊNCIA MODERNA E A GEO- GRAFIA: AVANÇOS E RETROCESSOS}

A Ciência Moderna encontra-se hoje em uma crise epistemológica causada por sua própria arrogância totalitária, seus diversos ramos, ou subdivisões, como propunha Descartes, acabaram seguindo rumos diferentes, não estabelecendo necessariamente um diálogo capaz de solucionar problemas complexos, principalmente quando a problemática acaba por envolver questóes de ordem social e de ordem natural.

Esta problemática, originada a mais de 400 anos, entre o que deve e o que não deve possuir o status de científico, tem conduzido mesmo nos dias atuais a um crescente fracionamento da realidade em sub-ramos da ciência, como destaca Guedes (2012):

A crise epistemológica constitui-se num fosso profundo levando ao fracionamento da ciência, onde cada sub-ramo cria seu próprio campo de ação, tendo como consequência a perda da unicidade do conhecimento e ao aprofundamento da hiper-disciplinaridade (GUEDES, 2012, p.121).

Guedes(2012) ainda continua:

Para a Ciência, foi interessante a divisão entre vários ramos, até o momento em que foi necessária para o fortalecimento do seu escopo, mas em contrapartida, levou ao esfacelamento do conhecimento do todo. Um bom exemplo pode ser apresentado na Medicina, como um ramo científico com fracionamento de especialidade a tal ponto, que perdeu a noçáo de cuidado do corpo como um organismo único, indissociável, criando subdvisões para cada "membro" do corpo, isto sem falar nas ciências psicológicas e sociais com suas sub-divisóes (GUEDES, 2012, p.122).

Nesse sentido, a Geografia apresenta o mes- 
mo problema epistemológico da Medicina, pois possui como objeto de análise algo que é indissociável, parafraseando Guedes, um "organismo único", intitulado espaço geográfico, que aliás se distingue totalmente do conceito de espaço absoluto preconizado por Newton.

A Geografia desde sua institucionalização acadêmica na primeira metade do século XIX, sempre se preocupou com a busca pela compreensão da relaçáo do homem (indivíduo ou sociedade) com a natureza (primeira ou segunda), ou seja, pela compreensão do espaço geográfico. Assim, o espaço geográfico apresenta-se como resultado histórico e dinâmico de relações e processos estabelecidos entre seus elementos, não como algo imutável, sem correlação direta com seus objetos, como visto no conceito Newtoniano. Sobre isso Harvey (1973) destaca:

Existe outro sentido em que o espaço pode ser concebido como relativo e eu proponho chamá-lo espaço relacional - espaço considerado, à maneira de Leibniz, como estando contido em objetos, no sentido de que um objeto pode ser considerado como existindo somente na medida em que contém e representa em si mesmo as relaçóes com outros objetos (HARVEY, 1973, p.13).

Dessa forma entende-se que é a relação entre os objetos que delimita o espaço, ou seja, não há espaço sem essa relação. Este conceito, como cita Harvey, estabelecido inicialmente pelo matemático e filósofo alemão Gottfried Wilhelm Leibniz, chegaria a Geografia através das obras produzidas por Alexander von Humboldt e Carl Ritter.

O espaço absoluto, ainda seria utilizado pela Geografia, mas não como conceito balizador da pesquisa, e sim no sentido de estabelecer a simples localização dos objetos.

Torna-se importante destacar que Humboldt e Ritter não utilizaram em suas obras o termo espaço geográfico e sim a noção relacional advinda do conceito de espaço leibziniano. Tanto Humboldt como Ritter pautavam suas análises na observação da paisagem, ou seja, a noção relacional de espaço era aplicada a análise da paisagem. O espaço relacional forneceu a base conceitual para a compreensão do espaço geográfico, este procedimento, no caso de Humboldt e Ritter, foi operacionalizado pela observação da paisagem.

A Geografia ao longo de sua história buscou operacionalizar a análise do espaço geográfico de diversas formas, estabelecendo para isso diversas categorias de análise, dentre elas podemos citar a paisagem, o ter- ritório, o lugar, a região e o ambiente, no entanto não é de nosso interesse neste artigo discorrer especificamente sobre cada uma delas e sim sobre a problemática da fragmentação científica na compreensão do espaço geográfico.

A questão que nos atemos aqui, e talvez a mais importante de acordo com o objetivo almejado, é de que a Geografia devido a seu objeto nasceu metodologicamente fragmentada, pois ao buscar compreender as relaçóes entre o homem e a natureza acabara adentrando dois eixos metodológicos distintos. Suertegaray (2001) sobre esta questão aponta que:

[...] a Geografia como área de conhecimento sempre expressou (desde sua autonomia) sua preocupação com a busca da compreensão da relação do homem com o meio (entendido como entorno natural). Neste sentido ela se diferenciou e se contrapôs as demais ciências, que por força de seus objetos e das classificaçôes, foram individualizadas em Ciências Naturais e Sociais. Este paradoxo acompanha a Geografia, ainda que hoje possa ser seu privilégio. Constitui um paradoxo, porque, na medida em que na Modernidade se expandiu a racionalidade e se constitui a ciência moderna, o caminho foi a disjunção, a separaçáa, a compartimentação do conhecimento; a divisão entre ciências naturais e as ciências sociais (SUERTEGARAY, 2001, s/n).

\section{A autora ainda complementa afirmando que:}

Em decorrência, a Geografia foi impossibilitada (pelo caminho que assumiu) de construção unitária e mesmo de um lugar preciso entre as ciências. Isto nos parece, dificultou, para a Geografia, a construção de um método, pois propunha-se a unidade natureza-sociedade num contexto científico onde estas dimensôes disjuntas perseguiam métodos diferentes (SUERTEGARAY, 2001, s/n).

O caminho assumido pela Geografia em sua emancipação enquanto ciência, como destaca a autora, é justamente o caminho do espaço geográfico. No entanto, apesar desta opçáo ter sido tomada a muito tempo, a Geografia, tanto no senso comum como no ensino, ainda permanece vinculada à noção de espaço absoluto. Fato que expressa justamente a noção errônea de ciência e principalmente de Geografia que adentra o imaginário da população pela porta da escolarização.

A dificuldade em se estabelecer um método único na Geografia também contribuiu para outro problema, pois possibilitou a criação de diversos grupos de pesquisa fechados, cada qual com seus métodos e objetivos.

Antes de mais nada é preciso frisar que não é intuito deste artigo propor um método único, que ultrapasse os resultados altamente especializados derivados dos grupos de pesquisa em Geografia, e sim uma refle- 
xẫo a cerca da possibilidade do uso dos diversos métodos voltados a um único objetivo geográfico, ou como destacou Moreira (2007) "antes tinhamos uma geografia com forma, mas sem conteúdo, e passamos a uma geografia com conteúdo mas sem forma" (MOREIRA, 2007, p.118). A forma a qual o autor se refere é justamente o objetivo refletido globalmente, aquilo que dá identidade a área do saber, o pensamento geográfico.

O que o autor afirma é que hoje temos uma quantidade enorme de conteúdos, no entanto confinados a grupos de pesquisa hiperespecializados. A falta de diálogo ou a falta de pensamento geográfico, não conduz os discursos a uma práxis transformadora, o que gera em alguns casos produçôes intelectuais inócuas, as quais são compreendidas apenas por seus pares.

Segundo Martins (2016, p.62), "o pensamento geográfico é geografia em pensamento", ou seja, a forma é resultado do conteúdo em pensamento, não de um pensamento unilateral, confinado a laboratórios, até por que de acordo com o objeto da Geografia isso não se torna possível. Atualmente a Geografia hiperespecializada vive em equívoco, reflexo de uma discussão epistemológica fraca e uma excessiva mercantilização do saber geográfico.

Nas universidades vivemos "uma cultura de reformas nas instituições de formação profissional universitária que visam garantir à formação: qualidade, eficiência, eficácia, produtividade, flexibilidade; maior vinculação ao mercado (ou aos mercados), às empresas" (CAVALCANTI, 2003, s/n). Esta perspectiva nada mais é que reflexo de uma sociedade construída sobre moldes utilitaristas, pragmáticos e de tempo rápido, sobre as quais:

[...] a ciência, a tecnologia e a informação tornam-se forçar produtivas fundamentais para o capital. Nesse contexto, as reformas da Educaçáo Superior brasileira devem ser compreendidas enquanto um processo de modernização, da racionalização com viés administrativo e econômico (CAVALCANTI, 2003, s/n).

No que se refere a Geografia, essa proposta não apresenta nenhum ineditismo, pois Varenius no século XVII já considerava o viés racionalista, administrativo e econômico como principal aporte teórico de suas análises geográficas.

A questão é que esta leitura que havia sido superada (não totalmente obviamente) pela análise do espaço relacional (geográfico), tem, por pressão mercadológica, retornado para as instituiçôes de formação universitária através dos SIG's (Sistemas de Informação Geográfica) e do geoprocessamento (não em todos os profissionais obviamente). Há um retorno a Geografia puramente racional pautada no espaço absoluto newtoniano, ou em outras palavras, ausente de métodos geográficos. Nesse sentido, Souza (2015) aponta que:

Na Geografia, a aplicação dos Sistemas de Informação Geográ-
fica obscureceu o conceito e sentido básico do espaço geográ-
fico, que da instância e categoria de análise social, torna-se ele-
mento formal de simples localizaçáo; onde o espaço geográfico
é entendido como geometria (SOUZA, 2015, p.38).

Dessa forma, muitos alunos acabam sendo cooptados por grupos de pesquisa, em alguns casos trabalhando nos projetos de seus orientadores, no intuito de após se formarem poderem adentrar o mercado de trabalho como técnicos em geoprocessamento, ou seja, a formação em Geografia por sua falta de clareza epistemológica e até de respeito próprio, possibilita uma simples formação técnica. Isto reflete claramente a falta de discussão sobre o papel da Geografia.

A crítica aqui não se dá diretamente aos SIG's e ao geoprocessamento, que são ferramentas de apoio fantásticas para a análise do espaço geográfico, a crítica se dá no sentido de sua ascensão ao nível de objeto de estudo da Geografia, nesse sentido a incoerência torna-se problemática até para a "manutenção" da Geografia enquanto Ciência. Saímos com muito custo da condição de apoio científico para novamente retornar a essa posição? Eis uma reflexão epistemológica a ser retomada.

A hierarquização universitária do saber assim como a hiperespecialização científica também tem atingido as licenciaturas, organizando inclusive um ciclo vicioso. Entendamos esse processo.

Primeiramente o aluno ao adentrar a universidade se depara com grupos de pesquisa fechados e componentes curriculares que em muitos casos valorizam mais os projetos individuais dos docentes do que a própria construção coletiva do saber científico do curso, na verdade a alienação de cunho mercadológico é tão grande que muitos alunos acabam se formando sem perceber as mazelas estruturais de seus cursos, há de certa forma também um comodismo vinculado a esta questão.

$\mathrm{O}$ aluno neste contexto acaba optando por afinidade por uma ou outra disciplina, até ai tudo bem, o problema é que este mesmo aluno acaba criando, em relação as demais disciplinas, uma certa aversão, quantas vezes já não ouvimos alunos se auto intitulando geógrafos físicos ou como geógrafos humanos? Isto reflete justamente a lógica dos projetos individuais organizados por professores hiperespecializados. Só existe uma Geografia em busca de um único objetivo, como veremos a frente. 
Dessa forma, o aluno acaba cursando Geografia sem ter a oportunidade de um debate profundo sobre qual é o seu real objetivo, até por que me parece que alguns docentes náo tem clareza de suas contradições, ou se tem, priorizam a manutençấo de suas zonas de conforto.

Outra questão importante repousa na falsa ideia de que a responsabilidade sobre a formaçấo de professores se restringe as disciplinas ditas "pedagógicas", o que fortalece uma ideia de divisão entre a construção e a transmissão do saber. Esse abismo se aprofunda ainda mais quando as disciplinas pedagógicas são lecionadas por especialistas externos a Geografia, que mesmo apresentando as melhores intençóes, não conhecem, ou conhecem superficialmente as discussóes epistemológicas que perpassam e perpassaram toda a construção do saber geográfico.

De acordo com Girotto \& Santos (2010), esta visão da prática pedagógica reflete justamente um projeto de sociedade que pressupóe a separação entre aqueles que produzem e os que transmitem o conhecimento.

Assim, o modelo de sociedade pautado na demanda de mercado atinge os futuros professores de Geografia de duas formas: a primeira, mais direta relaciona-se com as políticas públicas de educação, que adentram e impóe às licenciaturas um discurso cartesiano/capitalista de especialização para o mercado, sem distinguir as especificidades internas e externas dos cursos, a segunda, de forma indireta, se associa a transmissão de conteúdos isolados por docentes hiperespecializados, ou seja, que não permitem uma análise a partir de outras perspectivas, impossibilitando aos alunos imersões mais amplas e críticas no processo de entendimento do espaço geográfico. Em síntese, além da necessidade de rompermos a barreira da hiperespecializaçáo na produção do saber geográfico, precisamos romper a barreira da transmissão enviesada do saber.

Essa problemática resulta na formação de professores que dominam conteúdos geográficos específicos (na "menos pior" das hipóteses), mas que pela pouca reflexão acerca do todo, não possuem a capacidade de (re)construir através destes conteúdos seus verdadeiros significados sociais, dessa forma, a universidade e principalmente as licenciaturas acabam legitimando o status quo social através de um ciclo vicioso pautado na lógica de reprodução do capital.

Não basta, assim, ao professor de Geografia ter domínio da matéria, é necessário tomar posiçóes sobre as finalidades sociais da matéria escolar numa determinada proposta de trabalho, é preciso que o professor saiba pensar criticamente a realidade social e que se coloque como sujeito transformador dessa reali- dade. Da mesma forma, não basta a um bacharel em Geografia o domínio do conteúdo e de métodos e técnicas da pesquisa e do planejamento, da análise geoambiental, do sensoriamento remoto. É necessário que ele tenha uma convicção de qual é o papel que sua atividade profissional desempenha diante de um projeto de sociedade em construção (CAVALCANTI, 2003, s/n).

A Geografia, em todos os níveis de ensino, tem como dever a transmissão de saberes que sejam capazes de romper barreiras em favor de um projeto justo de sociedade, não em favor do acúmulo privado de capital. Este deve ser seu objetivo comum.

Que fique claro que o intuito náo é o de distanciar a Geografia das ciências exatas, e sim estabelecer um diálogo, uma vez que é função da Geografia, analisar e compreender problemas sociais em suas diversas nuances (econômicos, culturais, ambientais etc.), fornecendo assim todos os subsídios necessários para um desenvolvimento técnico de maior envergadura social. A Geografia nesta perspectiva tornar-se-ia indispensável para o futuro técnico/social e vice-versa e nesse processo se abriria novamente ao diálogo interno e externo.

\section{CONSIDERAÇÓES FINAIS}

Visamos estabelecer com este artigo mais do que uma crítica a influência da hiperespecialização científica sobre a Geografia ou uma crítica a estrutura mercadológica por detrás do ensino de Geografia, buscamos estabelecer um convite a reflexão: o que nós geógrafos entendemos por Geografia? Ou melhor, qual o significado do geográfico para a Geografia?

Entendemos que o geográfico para a Geografia baliza-se pela noçáo de espaço relacional, sobre o qual ocorrem todas as realizaçôes humanas, diferente do espaço absoluto newtoaniano. $\mathrm{O}$ espaço não é precedente a matéria, pelo contrário, a relação entre os elementos da realidade é o que configuram o espaço. A Geografia não deve se ater exclusivamente ao "palco da peça", entendido como simples receptáculo do acontecer, e sim ao "cenário", pois cada item componente da(s) cena(s) tem sua função no desenrolar da história, na composição da totalidade.

A partir disso continuaremos enfatizando que a Geografia, antes de tudo, Ciência Humana, deve possuir um único objetivo, independente do método de análise selecionado (dialética, fenomenologia, sistemas, etc.), que é o de fornecer, através da busca pela compreensão do espaço geográfico, melhorias para a sociedade e não para o acúmulo de capital privado. Este princípio que além de social é ético, deve permear todos os estágios da formação de nossos profissionais, pois só assim romperemos o ciclo vicioso ensino/especializaçáo/mercado.

Neste contexto, as questóes de cunho epistemológico da Geografia têm de voltar a discussão, tornando-se assunto de pauta em reuniôes de departamento, não ficando restrita apenas a "epistemólogos", afinal 
esta perspectiva de discussão teórica não se associa a uma outra área de especialização dentro da Geografia, como muitos insistem em afirmar, temos que pensar a epistemologia no conjunto do curso, ou seja, o pensar geográfico pautado em um objetivo social tem de ser construído coletivamente.

A Geografia necessita de uma reafirmação científica, suas escolhas têm de ser revistas, seu papel social tem de ser revisto, essa é uma tarefa urgente.

Encerramos este texto com uma reflexão de Armando Correia da Silva citada e complementada por Élvio Rodrigues Martins em artigo publicado em 2016: "Então eu constato a inexistência de um discurso geográfico teórico geral; e, como decorrência disso, ocorre uma fragmentação do conhecimento (SILVA, 1986, p.117). Eu só acrescentaria: e a fragmentação leva à perda do geográfico (MARTINS, 2016, p.79)”.

\section{REFERÊNCIAS}

BAUAB, F. P. Da geografia medieval às origens da geografia moderna: contrastes entre diferentes noçóes de natureza, espaço e tempo. 2005. Tese (Doutorado em Geografia) - Programa de Pós Graduaçáo em Geografia, UNESP, Presidente Prudente - SP.

BAUAB, F. P. A Geografia Geral (1650) de Bernhardus Varenius: a modernidade da obra. RA'E GA, v. 23, p. 191220, 2011.

CAVALCANTI, L. S. A formação profissional em geografia. In: ENCONTRO DE DIDÁTICA E PRÁTICA DE ENSINO (I EDIPE), 1., 2003, Goiânia. Anais do I EDIPE, Goiânia, 2003.

DESCARTES, R. Discurso do método. Porto Alegre: L\&PM, 2011.

FONSECA, F. P.; OLIVA, J. T. A Geografia e suas linguagens, o caso da cartografia. In. CARLOS, A. F. A. (Org.). A geografia na sala de aula. $3^{a}$ ed. São Paulo: Contexto, 2001

GIROTTO, E. D.; SANTOS, D. A. Daquilo que não falamos na geografia: repensando a formaçáo inicial do professor de geografia da educação básica. Revista de Geografia, V.27, no. 1, p.82-93, 2010.

GUEDES, J. A. A crise da ciência moderna e a busca de uma superação. GeoTemas, V.2, nº.2, p. 121-130, 2012.

HARVEY, D. Social justice and the city. Londres: Edward Arnold e Baltimore: John Hopkins University Press, 1973.

LOURES, M. V. R. As bases teológico-experimentais do espaço absoluto de Newton. PERI - Revista de Filosofia, v. 02 , n. 02 , p. $15-27,2010$.
MARTINS, É. R. O pensamento geográfico é geografia em pensamento? GEOgraphia, V.18, no 37, p.61-79, 2016.

MORIN, E. A cabeça bem feita: repensar a reforma, reformar o pensamento. Rio de Janeiro: Bertrand Brasil, 2014.

MOREIRA, R. Pensar e ser em Geografia. São Paulo: Contexto, 2007.

SANTOS, B. S. Um discurso sobre as ciências. São Paulo: Cortez, 2008.

SILVA, A. C. De quem é o pedaço? espaço e cultura. São Paulo: Hucitec, 1986.

SOUZA, M. A. As humanidades e a universidade: crise e futuro. Biblos - Revista da Faculdade de Letras da Universidade de Coimbra. no ${ }^{\circ}$ 1, 3a série, p.31-56, 2015.

SUERTEGARAY, D. M. A. Espaço geográfico uno e múltiplo. Scripta Nova - Revista Electrónica de Geografía y Ciencias Sociales, no 93, 2001.

THOMAS, K. O homem e o mundo natural: mudanças de atitude em relaçáo às plantas e aos animais (15001800). São Paulo: Companhia das Letras, 1988.

\section{Correspondência do autor:}

Francisco de Assis Gonçalves Junior fgjufmt@gmail.com Thamires Cristine Corrêa thami_cristine@hotmail.com

ARTIGO RECEBIDO EM: 09/02/2017

REVISADO PELO AUTOR EM: 13/06/2017

ACEITO PARA PUBLICAÇÃO EM: 13/06/2017 